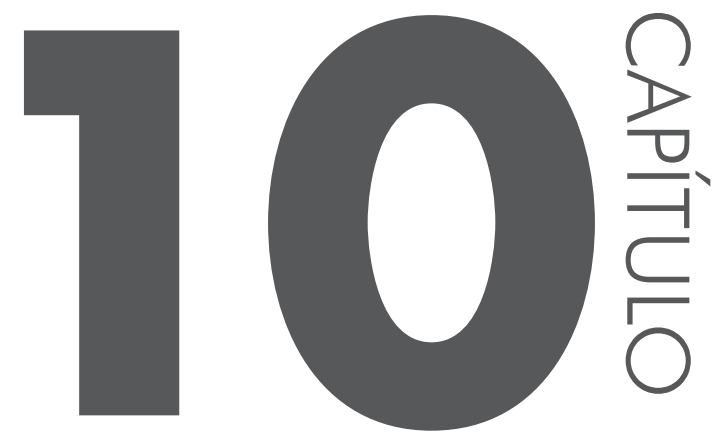

\title{
ATOS DE FALA TRADICIONAIS: FORMULAICIDADE E REPETIÇÃO NO USO DA LINGUAGEM
}

Lucrécio Araújo de Sá Júnior Universidade Federal do Rio Grande do Norte

\subsection{INTRODUC̣ÃO}

Neste capítulo, objetiva-se observar algumas fórmulas situacionais, constituintes discursivos de base sociocultural, a fim de exemplificar que no uso da linguagem existem expressões que se mostram cristalizadas e recorrentes, mas podendo ter graus distintos de fixidez. Embora repetitivos e tradicionais, tais fórmulas não podem ser analisadas sem que se observe o seu background (cf. SEARLE), uma vez que os modos tradicionais de dizer são instituídos por uma comunidade linguística que considera a sintonia entre a sua produção e o seu uso em situação performativa. 
O termo "polifocia" designa o fenômeno pelo qual, num dado contexto, se fazem ouvir vozes, que falam de perspectivas ou pontos de vistas diferentes com os quais o locutor se identifica ou não. Existem determinadas formas linguísticas que funcionam como índice da presença de outra voz, ou outras vozes que são transmitas geração a geração.

Os critérios para que uma sequência linguística possa ser considerada uma fórmula seguem os seguintes funcionamentos linguísticos-discursivos:

- se inscrever numa dimensão discursiva (situações de uso, evocação);

- funcionar como referente social (convencionalidade);

- se caracterizar por uma cristalização (repetição). (cf. TAGNIN, 2005; XATARA \& PARREIRA, 2011).

Uma expressão se aplica ao conceito de indiomatismo apenas quando seu significado não é literal, isto é, quando o significado da expressão não corresponde à somatória do significado de cada um dos elementos. Assim, bater as botas não significa “dar pancadas com os calçados”, mas quer dizer 'morrer' (cf. TAGNIN, 2005).

Dizemos que uma expressão se aplica ao conceito de fraseologia quando o sentido é literal e o significado é dado pelo conjunto de seus elementos e não pertencem a uma categoria gramatical específica. Nela se incluem todas as combinações em que os componentes são relativamente estáveis (em alguns casos a estabilidade é parcial permitindo algumas alterações, que não mudam o siginificado total da expressão), as expressões fraseológicas também podem possuir traços metafóricos. A fraseologia mais ampla envolve os indiomatismos, mas não é comum o contrário ocorrer.

- Exemplo: as fórmulas de citações em artigos científicos. Seguindo a perspectiva fraseológica, além dessas abordagens conceituais de formulaicidade e ideomatismo, existem outras, mas como neste estudo trataremos apenas das expressões formulaicas convencionais, seguiremos o postulado teórico da fraseologia. Não consideraremos os níveis fonológico e morfológico para nos concentramos nos níveis sintático, semântico e pragmático. Segundo Tagnin (2005), há expressões que são convencionais por estarem intimamente ligadas a um fato social e há outras em que o que é convencional é a sua forma. Alguns exemplos,

- Que horas são? É uma expressão convencional social, pois está ligada a uma situação.

- Isso são horas? 
Por outro lado, a expressão hora da onça beber água se estabelece como expressão convencional devido a sua forma, isto é, convencionou-se combinar os vocábulos para indicar que a situação é perigosa. Dizer a hora com essa fórmula poderá indicar uma situação, mas não uma situação rotineira; temos um ato de fala indireto, cuja força ilocucionária pode ser aferida sob um tom jocoso.

Referindo à estrutura linguística, a ordem em que os elementos ocorrem também pode ser resultado da convenção. Por exemplo, dizemos cama e mesa, mundos e fundos, café com leite, sempre nessa ordem. No momento em que a convenção passa para o nível do significado, entramos no campo da tradição, e as frases são compreendidas no âmbito da fraseologia e da indiomaticidade. Para nos comunicarmos, podemos fazer uso de expressões pré-fabricadas às quais recorremos frequentemente. Temos, assim, as fórmulas situacionais. Podemos citar algumas:

Fórmulas de polidez:

- Posso fumar?

- Você se incomoda de não fumar aqui?

- Será que eu poderia falar com você?

Expressões de quebra/retomada do turno da fala

- O gato comeu sua língua?

- Não tire conclusões apressadas!

- Não é o que você está pensando!

\section{Fórmulas de rotina}

- Olá!

- Bom dia! Boa tarde! Boa noite!

- Até logo!

- Até amanhã!

- Obrigado

- Desculpe

- Que esta data se repita por muitos e muitos anos.

- Bom apetite!

- O jantar está na mesa!

- Um brinde!

Palavrões e xingamentos: Alguns tipos de expressões, no entanto, costumam ser chamadas, pejorativamente, de 'clichê', sendo-nos recomendado evitá-las na 
linguagem culta padrão. Mas é preciso reconhecer que, no cotidiano, na conversação informal, as expressões formulaicas são bastante utilizadas. Não temos como negar o uso rotineiro de expressões fixas e consagradas, sejam essas expressões proverbiais ou palavrões. Quem nunca falou um palavrão que atire a primeira pedra! Temos ainda o fato da inovação do uso das expressões com o internetês: Vá pra PQP!!!

É muito trabalhoso estudar o fenômeno da formulaicidade se dependermos de nossa atenção para observar a recorrência de certas combinações. Fazer anotações sobre os usos que os falantes fazem no cotidiano é bastante difícil se quisermos dar conta de registramos os usos de tais expressões. Mas, com o advento do computador, é possível construir grandes bancos de textos e consultá-los com ferramentas computacionais apropriadas para detectar essas co-ocorrências e recorrências.

Para a Linguística de Corpus (LC), um corpus é uma coletânea de textos, necessariamente em formato eletrônico, compilados e organizados segundo critérios ditados pelo objetivo da pesquisa a que se destina. $\mathrm{O}$ formato eletrônico permite que esses textos sejam investigados e analisados automaticamente, com o uso de ferramentas computacionais específicas. A ferramenta que melhor permite observar as estruturas convencionais recorrentes da língua produz resultados na forma de concordâncias, em que cada linha apresenta a palavra ou expressão que está sendo investigada - a palavra de busca - inserida em seu contexto natural de ocorrência. Esse formato é denominado KWIC, ou seja, Key Word in Context e traz, em geral, a palavra de busca centralizada.

$\mathrm{Na}$ pesquisa, buscamos a concordância para a palavra Eita a fim de percebê-la como constituinte de uma locução tradicional do falar no Nordeste brasileiro. O corpus do estudo é composto de 7549 palavras, compreendendo os anos de 2000 a 2012. O formato foi denominado pelo KWIC, ou seja, Key Word in Context no programa para constituição de corpora na Web, o WebCorp.

Para a demilimatção das ocorrências, a pesquisa foi conduzida referente à compreensão dos múltiplos usos da palavra eita, convencionalizada como marcador discursivo conversacional basicamente intensificador de um ato de fala qualquer. Para configurar a formulaicidade, a palavra aparece associada a outras palavras, através das quais o sentido do enunciado se estabelece em situação contextual. Buscando uma concordância para a palavra "eita", encontramos:

- Eita mulesta, tem razão... Antonse vamo pegar o bode é cum as

- uma voz grave e ríspida responde: "Eita, cacete de telefone da porra! Alô? Autoelétrica,

- Cigano ...eita "pleura", fazia tempo que o Health não postava nada tão

- E AGORA? EITA LASQUEIRA, E AGORA? O bom colesterol não é tão bom quanto 
- e o presentinho e isso acontece...eita lasquera...coitado de quem tem conta!

- pra grudar no meu mega drive eita laskera to ficando velho + afinal e quem e q nao esta

- Será que eu morri dormindo?Eita, fudeu! Será que eu estou pagando pelas caixas e mais

- cada louco com sua mania kkkkkkkkkkkkkkk Eita Merda ... qqq merda --' Que que eu falei? Ó A MERDA O

- as crianças estao ficando emboioladas hj em dia... eita miseria!

Em se tratando da observação do contexto, como podemos notar, o contexto apresentado, na concordância acima, é truncado. Isso se deve ao tamanho do contexto pelo qual optamos, ou seja, 20 caracteres de cada lado da palavra de busca. Mas, no caso específico do concordanciador desse portal, esse contexto pode ser aumentado até 60 caracteres.

Se fizermos uma leitura vertical das linhas de concordância, isto é, se observarmos, por exemplo, as palavras que ocorrem à direita ou à esquerda da palavra de busca, verificamos alguns padrões. A concordância - abreviada para efeitos de exemplificação - permite identificar os seguintes padrões recorrentes à direita:

- $\operatorname{Eita}()$

- Eita mulesta (Eita muléstia)

- Eita pleura

- Eita Piula

- Eita miséria (Eita misera, Eita misera)

- Eita cacete

- Eita porra

- Eita caralho

- Eita buceta

- Eita fudeu

- Eita merda

- Eita lasqueira (Eita lasquera, Eita laskera)

Para chegarmos a um resultado de pesquisa satisfatório, foi necessário realizar o redimensionamento da busca. Uma vez estabelecidos esses padrões, podemos, com nova busca, verificar se, por acaso, as unidades detectadas fazem parte de uma unidade ainda maior. $\mathrm{Na}$ realidade é o que se verifica, principalmente, com eita mulesta:

- Eita mulesta dos cachorros!

- Eita () mulesta dos cachorros!

- Eita cachorra da mulesta! 
- Eita( ) cachorra da mulesta!

As ocorrências encontradas foram as seguintes:

- Natal RN, eita cidade bonita cachorra da mulesta.

- Eita saudade de Campina Grande da mulesta dos cachorros!!!!

- Aff.. falo direto!! Eita mulesta dos cachorro doido!! kkkkkkkkkkkk. Adoro..Não troco meu paraibanês por nada nesse mundo!! uma gota serena mermo!!

- Pernambucano quando se empolga, fica com a "mulesta dos cachorro". ... eita blog virado cá mulesta! kkkkkkkkkkkkk' mt bom o blog

- Eita farra doida da mulesta ... eita pagode bom da mulesta

- Eita transito cachorro da mulesta!

- Eita mulesta dos cachorros ainda tem tanta coisa prá acontecer.

- eita mulesta dos cachorro do capeta... ela deve tar sem credito! AHАНАНАНАННАНАНАНА.

- Eita mulesta dos cachorros, onde é que vai parar nosso acari véi de guerra minha gente? se até o prefeito está fazendo gato de energia

- ONILDO BARBOSA disse... tu ai com a mulesta dos cachorro prá escrever bunito menina . Eita gota. eu amooooooooooooooooooooo ...

- bunda de cobra, eita apelido feio da mulesta dos cachorro kkkkkkkk

Nas ocorrências, encontamos os intensifcadores de estados emocionais. As expressões que foram encontradas na pesquisa realizada ocorrem dentro de atos de fala expressivos, expondo estados emocionais dos enunciadores. São exemplos:

- Alegria: Bel Marko disse: Eita mulesta, kkkkkkkkk'

- Admiração: todos na jogada O Cabaré da Ciça sim, senhor... Eita, mulesta quem já se viu?! (Falado).A mulé era santa e

- Animação: eita mulesta imagine se desse ' pra ver p dente dele voando!kkk

- Felicitação: Curto muito uma boa piada e vindo do NORDESTE eita mulesta. é bom demais sô.

- Desejo: ibope vai ás ruas e a popularidade do Lula sobe.Eita mulesta dos cachorro!, será que agora vai chegar nos $90 \%$

- Espanto: quando ouvi um primeiro estrondo: POW! Pensei, eita mulesta, e agora? Tou sem estepe!... Quando vou olhar, tem

- Impaciência/revolta: Eita, prefeita ruim da mulesta dos cahorro!

Esses são exemplos do trabalho de esclarecimento da diferença entre usos empíricos e gramaticais dos enunciados. Muitas vezes um enunciado gramatical é apresentado como se estivesse sujeito à verificação empírica, quando, na verdade, 
não está. Essa análise recorda a crítica aos enunciados ditos sem sentido, que pretendem ser descritivos, mas não descrevem coisa alguma. As expressões formulaicas fazem parte de tipos de enucniados que desempenham uma função depois que seu papel de enucniados gramaticais tenha sido esclarecido. O trabalho do investigador dessas expressões consiste em mostrar o nonsense escondido na ideia de usar esses enunciados como empíricos, tornando evidente e patente o absurdo, mostrando sua função gramatical e reconduzindo, assim, o enunciado do uso "extralinguístico" ao seu uso normal (por exemplo, o uso para exprimir a própria sensação).

Uma breve análise, esboçada por Wittgenstein (no $\$ 66$ das Investigações Filosóficas), mostra que não é possível definir um grupo de propriedades que sirva para definir todas as possibilidades de usos e montagens das expressões. Encontramos, assim, uma rede de usos em que se pode encontrar semelhanças e diferenças nos usos das expressões em diferentes contextos. Não existe uma essência comum a todos os usos e exclusivo a eles; não existe nenhum conjunto de propriedades necessárias e suficientes para definir todos os casos no "jogo" da linguagem.

Isso não quer dizer que se possa usar as expressões de modo arbitário, uma vez que elas são mais ou menos cristalizadas. Com efeito, há transições e passagens intermediárias de um conjunto de propriedades para outro, de sorte que temos razões para chamar todos os casos com o mesmo nome: fomulaicidade. Não é uma questão puramente arbitrária que algo tenha ligado a si a expressão 'eita". Um esquema gráfico com uma sucessão de palavras pode dar ideias de passagens intermediárias. Carlos Penco (2006, p. 147) utiliza desenhos de rostos a fim de dar uma ideia desses exemplares de "famílias de expressões":

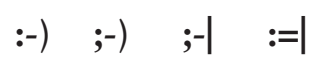

\section{Figura 11.1}

Na Figura 11.1, como observa o autor na sua versão estilizada, entre o primeiro membro e o último membro não há nenhuma característica comum, mas existem transições e membros intermediários que se apresentam de tal modo que dois membros próximos da série de figuras tenham sempre algo em comum.

De acordo com Penco (2006), a referência a transições e a famílias intermediárias de expressões traz à lembrança considerações análogas feitas por Goethe sobre o "método morfológico" para a classificação de plantas e animais. Essa ideia se refere ao que podemos chamar de esquemas ou protótipos. Há dois modos diferentes de usar uma fórmula:

i) como imagem de um exemplar;

ii) como imagem de um tipo, ou como esquema de uma série de objetos que, embora apresentados, são diferentes entre si. 
As reflexões de Wittgenstein, para o estudo das expressões formulaicas, nos permitem a discussão acerca de três temas centrais:

i) o tema do esquematismo e da imaginação;

ii) o tema da imprecisão e dos conceitos vagos;

iii) o tema da divisão do trabalho linguístico.

Aqui iremos nos limitar a destacar o terceio desses temas, baseado no conecito de delegação cunhado por Hilary Putnam (cf. PENCO, 2006). Por exemplo, a compreensão da palavra "neve" difere amplamente se ela está sendo usada por alguém que mora no Nordeste do Brasil, e por alguém que reside no Canadá. Como os falantes podem então se entender, se estão numa conversação, se as imagens, os conceitos, as crenças ligadas à palavra "neve" são diferentes em cada interlocutor? Temos a seguinte resposta,

i) antes de mais nada, o significado de algo é compartilhado pela comunidade dos falantes (que muitas vezes usam uma palavra delegando a outros a responsabilidade por seu uso correto ou pelo seu sentido exato);

ii) desse domínio comum faz parte também um esteriótipo tendencialmente comum a todos os indivíduos da comunidade, que constitui o "padrão mínimo" do conhecimento do significado de uma palvra.

Considerando os dois aspectos, é certo que nenhum falante sozinho conhece de maneira exaustiva o significado das palavras. O conhecimento do significado se acha distribuído na sociedade e os falantes normalmente "delegam" ("deferem”) aos pares muitos aspectos do significado, utilizando, na maioria das vezes, esteriótipos simplificados.

\subsection{PONDO UM PONTO FINAL...}

As expressões formulaicas citadas neste estudo são unidades lexicais que têm origens diversas em falares específicos que nascem nos meios mais periféricos da sociedade, com a intenção de falsear ou exacerbar o semantismo das palavras. Essa constatação nos permite corroborar o objetivo inicial a que nos propusemos no corpus coletado e verificar a existência de mecanismos coerentes e sistemáticos na criação de expressões formulaicas com base na conceituação de convencionalidade.

As expressões estão associadas aos palavrões e, por isso, provocam uma sensação de transgressão ao serem pronunciados, afinal de contas, trata-se da liberdade linguística de expressar-se no cotidiano. Por outro lado, as expressões asseguram o valor lúdico aos enunciados que constituem, designando temas-tabus da linguagem comum. 
Os estereótipos certamente constituem um desenvolvimento original sobre os conceitos de usos de expressões por semelhanças contextuais e sobre o uso esquemático de imagens ou paradigmas linguísticos. O debate em torno dos conceitos de estereótipo e de delgação reforçam a ideia de que é necessário encarar em separado dois aspectos da investigação semântica, distinguindo os seguintes problemas:

i) como fixar a referência das expressões do léxico;

ii) como podemos dizer que "compreendemos" a liguagem, embora nem sempre os nossos atos individuais de referência acertem perfeitamente o alvo.

Esse último tema é o tema da competência léxica, isto é, da capacidade de se orientar no léxico de uma língua de modo que saiba usá-la, de sorte que se possa ser considerado falante competente. Para isso, a competência léxica possui dois aspectos: a competência inferencial, que é a parte da competência que conceta todas as palavras do léxico em uma rede chamada geralmente de "rede semântica" - uma rede semântica é uma representação das relações entre as palavras do léxico e pode ser representada por postulados de significado; e a competência referêncial, ou seja, a capacidade de associar objetos, contextos, conceitos e abstarções variadas.

\section{REFERÊNCIAS}

ALVAREZ, M. L. O.; UNTERNBAUMEN (Org.). Uma (re) visão da teoria e da pesquisa fraseológicas. Campinas: Pontes Editores, 2011.

CALVET, L-J. Tradição oral \& tradição escrita. Tradução de Waldemar Ferreira Netto e Maressa de Freitas Vieira. São Paulo: Parábola, 2011.

MOTTA, A. R.; SALGADO, L. (Org.). Fórmulas discursivas. São Paulo: Contexto, 2011. PENCO, C. Introdução à filosofia da linguagem. Petropólis: Vozes, 2006.

ROCHA, C. A. de M.; ROCHA, C. E. P. de M. Dicionário de locuções e expressões da lingua portuguesa. Rio de Janeiro: Lexicon, 2011.

TAGNIN, S. E. O. O Jeito que a gente diz: expressões convencionais e indiomáticas inglês e português. São Paulo: Disal, 2005. 
